\title{
The Critical Thinking for MOOC and Teaching of Universities under the Popularity of "Internet Plus Education" in China
}

\author{
Lijun Yang \\ Southeast University \\ Nanjing, China \\ Huanghe Science and Technology College \\ Zhengzhou, China
}

\begin{abstract}
Internet plus" is very popular now in China, Internet has combined all walks of life. Facing this upsurge, we need more rational thinking. "Internet plus Education" is bound to innovate traditional higher education, but undoubtedly there still are a lot of problems. This paper proposed such following views: the popularity of MOOC is only local in China; the biggest beneficiary of MOOC are those students of non famous universities; we should judge the quality of MOOC with the teaching of the course and promote a virtuous cycle development, and MOOC can serve as a useful tool in the traditional teaching of universities too; both MOOC platform and teachers should pay attention to the quality of MOOC, which needs a specialized MOOC production team because specialist only masters his own field; MOOC do not own the credit basis which can be widely accepted by the society, so it must be combined with off-line traditional teaching of universities; we should consider dialectically the advantages and disadvantages of MOOC, and there is no need to worry about the replacement of the traditional teaching completely.
\end{abstract}

Keywords-“Internet plus Education"; MOOC; traditional teaching; social approval

\section{THE REFORM OF "INTERNET Plus EDUCATION" TO THE TRADITIONAL TEACHING OF UNIVERSITIES}

MOOC is a kind of large-scale and open course, one of the forms of "Internet plus Education" as well. Unlike the traditional on-line courses, it has a broader space for development, learners of MOOC can be conveniently online learning after registration of network, thus time, region, language, education and resource limits are broken through, both sharing of global fine resources and teaching of famous universities may be realized also. Theoretically, besides technical innovation, breakthrough of "Internet plus Education" mainly includes the following aspects.

\section{A. Breakthrough of Teaching}

In the process of the traditional teaching of the universities, teachers and students are limited in the classroom and teachers play an initiative role, but time of class is limited, it is impossible for them to wait for each student's good grasp, thus they can not teach students in accordance with their aptitude.
Finally the students with poor foundation will not understand the curriculum theory timely and easily lose their interests and confidence in learning.

The "Internet plus Education" may change the way of thinking of teachers and students in the traditional teaching by means of the Internet, so the teachers and students may be partners of learning. Teachers can pay more attention to the learning needs of students and their teaching methods are more flexible, such as MOOC, flipped classroom, micro classes and mobile classroom etc take the cloud as a cognitive tool to share educational resources, support the inquiry of students, make games and learning style of one on one etc. The teachers provide the course resources, then guide the students and help students to solve problems, hence students can take over the initiative to choose the teacher and the classroom, and then the course of "private custom" is achieved also.

\section{B. Breakthrough of Mode}

Traditional teaching time of universities is fixed in advance, the teaching is restricted to the teaching materials and plan, and students have to go to the classroom on time. If students miss this time, they will lose the opportunity of attending the lecture. Moreover the students can only ask their questions after the class or the time arranged by the teacher ahead of schedule, apparently it is not allowed to ask questions in the classroom casually. Thus questions are accumulated so many that the students learn difficultly this course naturally. "Internet plus Education" may change the teaching mode, and more people outside the classroom can widely participate in the study of course, teachers and students communicate with each other more smoothly too. Without restriction on the region, time and teachers of the traditional teaching, the highquality educational resources may quickly be spread, so more learners reduce the unequal distribution of educational resources.

In the process of traditional teaching of universities, teachers write on the blackboard or whiteboard, and students use a mobile phone to play but not to learn in the classroom. However through "Internet plus Education" teaching students interact with the teacher through the barrage on the slide, the 
mobile phone or the computer may be taken as a learning tool, thus according to the students' feedback the teacher makes timely interaction and adjustment of teaching contents, methods and speed.

\section{Breakthrough of Evaluation}

In the traditional teaching of universities, the teachers make an evaluation of the students mainly in accordance with the results of final examination. Even many students make cheating without the correct attitude to study in order to pass the exam or get a better final exam grade. In addition to the final exam grade, there is the regular grade provided subjectively by the teachers usually, and the later is difficult to be quantified. This evaluation of traditional teaching neither fully reflects the students' learning process, nor fully does stimulate the enthusiasm of students' active learning.

But "Internet plus Education" based on applications of large data, the each time, each learning evaluation, each question, feedback of teachers the students can all be used as data of information which is taken as the objective basis of evaluation, thus the bottleneck of traditional teaching evaluation is broken through.

\section{PROBLEMS OF "INTERNET Plus EDUCATION” - MOOC}

In theory the "Internet plus Education" - MOOC makes a great breakthrough the teaching of universities, but in fact there are such following problems.

\section{A. The Quality Identification and Evaluation of the MOOC}

1) The quality identification of the MOOC: The quality of the MOOC courses is very important, but it is still not clear how to determine the quality of the course now. Usually the MOOC courses require three elements: elite teachers, elite schools and elite courses, but such elements are extended with the heat of "Internet plus Education" and more and more MOOC courses and platforms come out. The MOOC courses possessing simultaneously the three elements are too limited to meet the development of MOOC platform and various learning purposes. So some non famous teachers with higher teaching level in non famous universities are likely to participate in the MOOC in order to improve their fame and so on. In addition at present the vast majority of students give up halfway that may not make an objective evaluation of the quality of the course. Usually the MOOC quality evaluation of learners mainly is decided by whether it's stronger theory, or easier to be understood, and or more interesting, contacting with reality closely and so on. So many standards of evaluation of quality may result in the unified production standards for MOOC class, and the students will get different learning effects finally.

2) The evaluation of MOOC courses: Evaluation and feedback are the important distinction between the MOOC with the previous network video courses, but in the actual operation the evaluation of MOOC for learning effect is not as good as the theory. Now the evaluation methods of MOOC include the multiple choice questions corrected by machine, open simple answer test and the mutual evaluation among students. Because there are too many students, the second evaluation method is very few, and the other two methods are more. The first method may ask learners who get lower scores to review the previous requirements, and this evaluation is just the traditional curriculum evaluation from off-line to online, although it is modified by computer, still high level test questions need to be designed by MOOC teachers. There is too many questions about mutual evaluation among learners, the more number of learners, the more assignment evaluated by them, moreover in the process of evaluation there is no teacher to make any supervision and guidance, consequently the evaluation results are not objective as well as traditional evaluation, it will hit enthusiasm of learners, and there's no doubt about that. When on-line discussion, one problem will soon be obliterated by others' because of so many learners. The biggest difficulty of such three evaluation methods is: it can not effectively prevent students from cheating, so there will not be really objective and accurate evaluation results.

\section{B. The Quality Control of MOOC Courses}

1) Quality control by the MOOC platform: Generally the MOOC platform construction is inseparable from the high teaching quality of universities, such as the following three MOOC platforms: Coursera, edX and Udacity, the former two were set up by the universities. The first was founded by Stanford University, edX by the Harvard University and the Massachusetts Institute of Technology. The first MOOC was established by Tsinghua University at 2013 in China which named "School Online"; and then NetEase and Higher Education Press jointly established "Chinese University MOOC" providing high quality courses of many famous universities in China; another Shanghai Jiaotong University founded the "Good University Online" etc. Higher education is different from other tangible goods, and MOOC platform is also different from other e-commerce trading platform too, so MOOC platform should provide high quality of courses and strictly select courses, appropriate evaluation mechanisms need be established too. Obviously more courses and bigger websites do not mean higher quality of MOOC, and "Internet plus Education" does not be equal to the simple teaching from the off-line to on-line, thus certain IT information technology maybe good for MOOC to operate better.

2) Quality control by the MOOC teacher: Referring to "Internet plus Education", besides the quality of MOOC courses is decided by platform, the teachers are also important. Without a special video production team, teachers need equip themselves with manpower and equipment, video production etc to manage the courses from off-line to on-line. Teachers themselves of universities have a lot of teaching, scientific research and other relatively heavy tasks, thus their spare time is relatively little, and they can hardly afford the management of MOOC themselves. Except relying on commercial MOOC platform, teachers of university who participate in the MOOC almost receive no reward, their input and return is not 
proportional, so it will give a blow on the enthusiasm of teachers participating in the MOOC. Now there is no effective incentive mechanism to attract and promote the teachers to continuously participate in the MOOC. In the long run, the lack of incentive mechanism of teachers' participation in the MOOC is not conducive to the sustainable development of MOOC.

\section{Social Approval and Certification of MOOC Courses}

1) The social approval of MOOC courses: The college graduates are facing the grim employment situation, and generally students participate in the MOOC in addition to the interest, and also the social approval after finishing their MOOC courses. The participation of the MOOC courses was not approved by society, besides the lack of effective restraint to urge them to complete MOOC courses, so the loss of students is very serious in the process of MOOC learning. Covering "Internet plus Education" MOOC course itself, learning initiative of students is very important, so if there is a wide social approval, students will be encouraged to learn further, the advantages of this approach will be maximized. As is known to all the credit of MOOC courses in China has not been widely accepted by the society. Even there are only a few universities accept MOOC course credits in other countries, and the students can complete a MOOC course of university and get the university's credits, such MOOC credit can be exchanged with the traditional credit of the school also. However social approval of MOOC course credit is very low in China, although the students get the credits, they can not be accepted by the enterprises still.

2) The certification of MOOC courses: In order to obtain social approval, they first need to obtain certification of courses, and certification of courses should be able to demonstrate the students have mastered the knowledge of this course. However the exact certification of courses is very difficult, through the "Internet plus Education" who really is learning at the other side of the Internet is difficult to be determined, such asymmetry of information leads to the certification does not possess enough credit foundation widely accepted by the society, so that the traditional teaching is bound to get more approval than MOOC. At present the threshold of MOOC certification is low, the students can easily get a certificate, but people generally believe that the quality of certificate is in the direct ratio to the difficulty of obtaining it. If MOOC certification is too difficult, the students will pay more attention, but also a lot of poor selfconfidence students may give up learning of the MOOC courses. A high degree of difficulty can only attract a small part of good students and those with a high interest in them to complete the courses. Therefore, now universities need to balance the difficulty of certification of courses against social approval. In addition, even a certificate is not equivalent to the credits, because most of universities do not accept the credits of MOOC courses.

\section{The Understanding of MOOC and Teaching}

1) The insufficiency of knowledge: "Internet plus Education" MOOC will bring great changes to traditional teaching of universities. Many universities have not yet felt the craze of "Internet plus Education" in China, and nearly all their teaching methods are the traditional teaching methods. Some universities do not understand, avoid or even exclude "Internet plus Education", teachers make mainly use of the Internet to query the data of their courses, so MOOC teaching methods have not been widely used. Teaching infrastructures of some universities are not perfect, for example shortage of multimedia teaching equipment results in the impracticability of MOOC teaching. Even owning the hardware condition of MOOC teaching, they keep skeptical attitude to MOOC and worry that MOOC will squeeze the living space, in addition to limitation of teachers, there is no large-scale promotion of MOOC teaching. Students are influenced by their school, so they hold the same attitude too. Even if there are some students understanding the MOOC, because of constraints of the education system in China, also they won't take the MOOC as their study of courses. Teachers are the main body of curriculum teaching, but many teachers also have insufficient understanding to MOOC in China, they overestimate or underestimate the difficulty of the MOOC teaching and do not know clearly the role of MOOC teaching, thus even more passive and conservative attitude are kept by them.

2) The one-sided understanding: First, the MOOC courses are considered the same as the open network class. MOOC have similarities with the latter, and both of them are largescale, open and online courses, but the former is more interactive between teaching and learning as well as among students than the latter, moreover the courses of the former are more vivid and students take more initiative in learning. Referring to the latter, most of the universities directly uploaded the curriculum teaching materials and teaching syllabus etc. on the Internet, although some instructional videos are uploaded too, there are no assignments and process of certification and so on, then the students still in the state of passive learning, thus it is the teaching of courses from offline to on-line. Second, the "Internet plus Education" MOOC are endowed too high expectations. In fact, MOOC has its own inherent disadvantages, and thus it can not completely replace the traditional curriculum teaching of universities. There are a lot of people with too high expectations of the MOOC, and even believe that MOOC must threaten the traditional teaching of universities. Actually it is completely unnecessary to concern it. Teachers of universities can make their own guidance to the teaching of the MOOC for their own services.

\section{THE CRITICAL THINKING FOR MOOC AND TEACHING OF UNIVERSITIES}

Facing the "Internet plus Education", we should keep calm. MOOC can not only completely overthrow the existing off- 
line Higher Education, but also can further improve really its flaw, and make more people enjoy more high-quality educational resources at lower cost, eliminate the unfair distribution of educational resources too. "Internet plus Education" MOOC further promote the traditional teaching and make common development of teaching and education from offline to online.

\section{A. Innovations of the Evaluation of MOOC Quality}

1) The innovation of the quality identification of MOOC: Universities may combine quality certification of "Internet plus Education" MOOC with traditional teaching of courses. As far as China is concerned, colleges and universities do not make extensive promotion and application of MOOC, thus the development of MOOC is restricted, even many universities keep MOOC at a distance. In fact MOOC heat is only a local heat, and it is "a small minority of the game" just among many famous universities, but the education mass are large number of non famous colleges and universities in China, and they are really the biggest beneficiaries of MOOC. From the point of view of the short board effect of "bucket theory", it is very important to make up short board for improvement of the overall teaching level in China, so "Internet plus Education" is a favorable opportunity. To increase spillover of knowledge and technology and diffusion rate, with the help of "Internet plus Education" the elite higher education resources may be used to combine the traditional teaching of courses. Thus we can see MOOC may also serve as teaching tools of traditional teaching. Quality identification of MOOC can be combined with the teaching of universities, standards of quality recognition may be set according to whether students have mastered the knowledge and what extent of their mastering, if the students master more knowledge, and then MOOC quality should be higher, and these are easily found through the process of traditional teaching. Although in theory, large data can understand the learning of students, but it can not completely eliminate the asymmetric information, so it is necessary to identify the quality of the MOOC with combination of off-line teaching.

2) The innovation of the evaluation of the MOOC: Now there are three kinds of evaluation methods: choice questions corrected by machine, open simple answer test and the mutual evaluation among students, which more or less have defects. Obviously the defects may be made up through the following aspects: more responsibility and dedication of teachers, more integrity and trust among the students, and technical innovation etc, yet all these can not make fully an objective and accurate evaluation of MOOC. If students just depend on their interests and hobby to self-study MOOC courses without supervision and management of teachers, the dishonest evaluation of MOOC and "drop out" may be solved difficultly still. Then through combining with the traditional teaching, they complement one another perfectly. The total score of the latter contains the final exam and regular grade, then to take one MOOC course which students are interested in as part of the regular grade, evaluation of MOOC may be realized. Such evaluation of this MOOC can also promote the evaluation of traditional curriculum teaching. Another example, teachers set some knowledge of MOOC designated by them in the final papers randomly to test whether students really master the knowledge of MOOC.

\section{B. The Quality Control of the MOOC}

1) Control of quality by the MOOC platform: It is the principle of platform in the screening course to put quality before quantity and make sure the best resources of courses in their platform. MOOC itself does not require each university and each teacher to involve and only need the elite participate in it, but the promotion and application of the MOOC courses should be widely spread in the China's universities. Learning from experience of other e-commerce trading platform, MOOC platform may control the quality of MOOC courses from the evaluation mechanism and establish the mechanism which students can feedback the quality and give a mark of the courses through it. Through the analysis of data, the bad courses should be monitored closely, if it is turned out to be true, then make perfect them or directly withdraw them. The platform should select the best quality of courses to the best of its ability.

2) Control of quality by the teachers: In fact off-line teaching of "Internet plus Education" is extremely important too, online and offline should be matched with each other well. The teachers should better control the quality of "Internet plus Education" MOOC too, first they should improve the quality of off-line courses, the courses knowledge and interest in one, teaching clear and well organized in one as well, and then obscure knowledge may be easily understood.

One might have learned the doctrine earlier than the other, or might be a master in his own special field, so besides a good lecturing by MOOC teacher, MOOC production team is necessary who may provide technical support for the MOOC teacher. Establishment of incentives and allowances for MOOC excellent teachers is necessary. Moreover teachers can guide the students to pay more attention to the higher level of quality MOOC courses according to the characteristics of the students, for students can not tell the quality of MOOC prior to their studying, and thus it is beneficial to improve the teaching effect and the students' knowledge level too.

\section{Social Approval and Certification of Courses}

1) The countermeasures to improve the social approval: Compared with the traditional university curriculum, opportunity cost of MOOC is low, social recognition is directly proportional to the opportunity cost usually. So MOOC can improve its social recognition through integration with traditional teaching of universities. Some MOOC curriculum set by the universities in each semester can be appropriately specified as elective courses of the students, students may choose their favorite lessons to learn according to their own situation. If the students choose one MOOC course, in addition to the learning of after class, the school 
may set a small amount of classes for the students and teachers to discuss. Teachers may urge and guide students to learn MOOC courses, assessment is necessary at the end of the semester, award those checked out all right the same credits as other traditional elective courses. If they can not pass the examination, they have to retake this course too. The students are bound by system of school, MOOC drop out rate will be greatly decreased and will get more social approval by means of traditional teaching, and thus both the MOOC and the traditional teaching can form a virtuous circle. If some graduate students have taken some MOOC courses and obtained formal credits of the university, it will be very useful for their employment or further study in future. This kind of combination between MOOC on-line and off-line teaching actually increases the opportunity cost of learning MOOC courses.

2) The countermeasures to make MOOC curriculum certification: At present, the first problem of curriculum certification is how to confirm the true identity of students, and it can be solved through the integration of the MOOC and the traditional teaching, namely on-line learning, off-line assessment. MOOC curriculum certification need be made by setting up special off-line MOOC curriculum assessment agencies for the learners of MOOC who are not students in the universities in order to really prove that learners really grasp the relevant knowledge of this MOOC course. Obviously "Internet plus" is not a panacea, although "plus" the Internet, a lot of problems still need to be solved off-line. Second, choose what degree of difficulty of curriculum certification. MOOC courses are used to transmit knowledge, and we treat knowledge should be extremely serious. Although low threshold can allow more learners, certification of courses should be careful still. It not appropriate to reduce the certification standards because trainees themselves levels are low. If learners quit or do not work hard, then they should not get the curriculum certification. "Internet plus Education" may give students a certain freedom and flexibility, but not complete slack and neglect. Getting curriculum certification is a prelude to the credit, and then through combining with offline teaching, it is fully feasible to get credit and approval.

\section{Objective Understanding of MOOC and Teaching of the Universities}

1) MOOC can not replace the traditional teaching of universities: Compared with the traditional teaching of universities, the MOOC contains the following disadvantages: First, there are too many students, thus an online message of individual student has not been immediate attention and thinking, and then it is buried into messages of too many other students promptly. Teaching students in accordance with their aptitude does not work when there are too many students. Second, theoretically there will be more interactive between MOOC teachers and learners, but in fact the communication effect is not good because teachers and students can not meet each other, the teacher can not make better supervision and management of students. Students difficultly obtain enough mutual trust without meeting each other, thus good emotional ties may not be formed like the traditional teaching. Consequently, the interactive learning of MOOC is even worse than the traditional teaching. Third, even if the learners of MOOC can get certification of courses and credits through the "Internet plus Education" only which may not be widely accepted by the society due to the existence of information asymmetry, so it is not conducive to the learning of students and sustainable development of MOOC. Fourth, although time of MOOC learning is free, it is not enough to bind students, the vast most of the students are unable to adhere to complete their MOOC, but the constraints of traditional teaching can force students to study well. To summarize, MOOC can not completely eliminate the traditional teaching of universities.

2) The relationship between the MOOC and the traditional teaching of universities: In fact, MOOC and traditional teaching can be complementary advantages, connect and impact each other well. At present, there is a tale of two worlds about "Internet plus Education" in China, a large number of educational resources are not fully utilized which shows actually the improper allocation of educational resources. People need to realize the idea first, that is "Internet plus Education" MOOC is just a mode of education and it can be combined with traditional teaching well, and thus universities should make full use of this kind of education mode in China. A small number of courses in the classroom can be selected to adopt MOOC teaching method, some of the links of MOOC may be applied in the traditional teaching from online to off-line also, then the traditional learning effect may be strengthened but the defects of MOOC may be weakened. The spread of mobile phones in China's universities can be made fully use of to carry out the combination of MOOC learning with offline traditional teaching. Universities should actively guide students and teachers to use MOOC teaching, closely follow the trend of the times, guarantee the benign cycle of MOOC and the traditional teaching from the design of the rules and regulations, and make whole promotion of the teaching level in China.

\section{REFERENCES}

[1] Jon Baggaley. MOOC rampant[J]. Distance Education, 2013, Vol.34 (3), pp.368-378

[2] Jeremy Knox. Digital culture clash: "massive" education in the Elearning and Digital Cultures MOOC [J]. Distance Education, 2014, Vol.35 (2), pp.164-177.

[3] John R. Drake, Margaret T. O'Hara, Elaine Seeman. Five Principles for MOOC Design: With a Case Study[J]. Journal of Information Technology Education: Innovations in Practice (JITE:IIP), 2015, Vol.14, pp.125-143.

[4] Riismandel, Paul. Video Makes the MOOC[J]. Streaming Media Magazine, 2013, pp.61-62.

[5] Turner, Loren. Case in Point: HOW TO MAKE A MOOC[J]. Computers in Libraries, 2015, Vol.35 (7), pp.10-13. 